\title{
DETERMINAÇÃO DË ZONAS DE VENDAS: UM MODELO BRASILEIRO
}

RAIMAR RICHERS

\begin{abstract}
"Territórios de venda oferecem ao prciutor um sistema organizado para [.. $]$ \& cobertura e o assessoramento de todos os pontos de venda na proporção exáta do faturamento esperado, evitando, ao mesmo tempo, a durílicação de esforços de venda e a realização de viagens onerosas e desnecessárias." Francis E. HUMMEL
\end{abstract}

"O todo é maior do que a soma de suas partes" - afirma antigo axioma filosófico. Apesar de matemàticamente absurdo, êsse enunciado tem profundas raízes empíricas . O presente artigo descreve e analisa uma aplicação dêsse princípio. Partimos da observação de que a emprêsa -qualquer que seja o seu tipo ou tamanho - se depara com um mercado composto de múltiplas variáveis, cujo equacionamento é essencial à racionalização do processo distributivo, mas tão complexo que não pode ser prontamente compreendido como um todo. Apenas a análise das partes componentes do mercado total permite o conhecimento das fôrças prełominantes que nêle atuam, a partir das quais são esboçados e executados planos racionais de ação mercadológica. Assim, o todo cresce em função do conhecimento pormenorizado de suas partes.

O chamado "zoneamento de vendas" (ou segmentação geográfica do mercado) é um dos instrumentos que se desti-

RaImar Richers - Professor-Adjunto, Departamento de Mercadologia, Escola . de Administração de Emprêsas de São Paulo. 
nam a êsse objetivo de equacionamento e racionalização do esfôrço mercadológico. Ao aplicá-lo a emprêsa cria condições para:

- a determinação racional do número de pessoas (vendedores, gerentes de filiais, inspetores etc.) que participam do processo de distribuição;

- a remuneração, supervisão e avaliação dessas pessoas;

- a seleção e o contrôle do tipo e do número de filiais, armazéns, depósitos e intermediários essenciais à mercadização;

- o transporte e a comunicação eficiente entre o escritório central (ou a fábrica) e os mercados regionais;

- a distribuição e a medição da eficiência do esfôrço promocional;

- a elaboração das previsões de venda;

- a fixação das cotas de venda; e

- a avaliação do mercado em função dos tipos de fregueses, dos concorrentes e das tendências de evolução da demanda regional.

Em suma, a segmentação geográfica é valioso instrumento de contrôle e redução dos custos mercadológicos, aplicável por tôdas as emprêsas que dependam da eficiência de um corpo de vendedores ou intermediários, e que distribuam seus bens a clientelas localizadas em praças mais ou menos dispersas. Entre essas emprêsas se situam tôdas as grandes e médias produtoras de bens industriais e de consumo, além dos grandes atacadistas. Apenas para a maioria dos varejistas e para muitas indústrias pequenas a segmentação geográfica oferece pouca ou nenhuma vantagem.

Apesar, no entanto, de suas amplas oportunidades de aplicação, muito restrito parece ser o número de emprêsas nacionais que se utilizam do instrumento da segmentação, o que atribuímos, em parte, à falta de divulgação de sua técnica e de suas vantagens operacionais . 
Propomo-nos, pois, a expor um modêlo de segmentação geográfica que possa ser aplicado pela emprêsa nacional, desde que esta o adapte às condições internas e externas que caracterizam os seus métodos de produção e distribuição. Ao expor êsse modêlo, visamos a conjugar os princípios gerais da segmentação com a experiência observada de emprêsas nacionais que há anos procuram racionalizar o seu processo de distribuição a partir de uma quantificação objetiva do seu mercado. Um exemplo ilustrará a maneira pela qual o modêlo poderá ser aplicado na prática adrninistrativa .

\section{DESCRIÇÃO DO MODÊLO}

A tarefa de segmentação abrange dois aspectos tècnicamente distintos. O primeiro consiste na coordenação dos dados estatísticos referentes aos potenciais regionais; o segundo compreende as decisões administrativas a serem tomadas no decorrer da implantação. E a partir dessa divisão que devemos esquematizar o modêlo, como segue:

A) Determinação dos Potenciais Regionais

1. Levantamento de dados internos.

2. Levantamento de dados externos.

3. Determinação dos índices regionais.

B) Decisōes sôbre a Cobertura Geográfica

4. Determinação das diretrizes de penetração regional.

5. Seleção dos mercados e determinação das "metas de penetração regional".

6. Seleção dos centros operacionais .

7. Agrupamento dos mercados regionais.

A Figura 1 procura dar uma visão de conjunto das sete fases do modêlo e da maneira pela qual essas fases podem ser integradas na prática administrativa. 


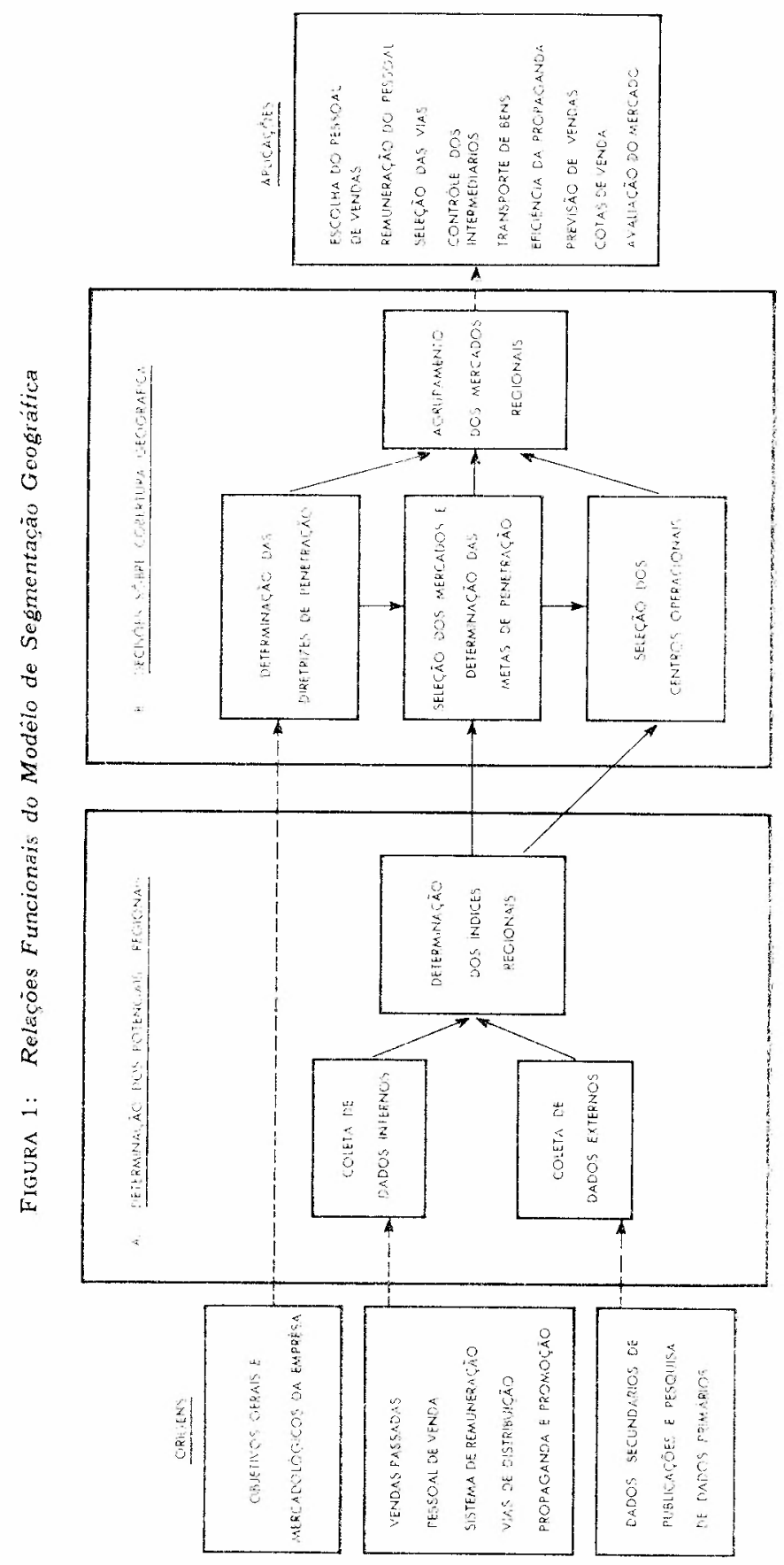




\section{A) Determinação dos Potenciais Regionais}

Por onde começar? - é a dúvida que costuma assaltar o técnico ao enfrentar uma tarefa nova e complexa. Geralmente, o melhor início consiste em coletar e agrupar todos os dados que tenham relação direta com o problema a ser resolvido. Daí recomendamos: iniciar a tarefa com a coleta dos dados internos e externos que devam ser coordenados em face dos objetivos específicos da segmentação.

1. Levantamento de dados internos - $\mathrm{O}$ passo inicial do plano é, pois, a coleta dos dados internos diretamente pertinentes à tarefa proposta. É natural que êsse levantamento dependerá, em parte, do tipo de emprêsa e de sua organização. Geralmente, contudo, os dados de maior utilidade para o plano são os abaixo expostos .

- Vendas do passado: uma noção preliminar dos potenciais regionais e da eficiência relativa do setor de vendas pode ser obtida através do levantamento de dados sôbre volume de vendas de anos passados nas diversas praças.

- Número, tipo e qualificações do pessoal de venda: as funções a serem exercidas pelo corpo de vendedores e por seus superiores (inspetores ou gerentes distritais), o grau de instrução e o treinamento do pessoal são alguns dos elementos que devem ser levantados. Êsses elementos devem ser lançados em fichas de que constem, também, os principais dados pessoais de cada vendedor, como residência, idade, estado civil, remuneração, eficiência e até algumas indicações sôbre atitudes e predileções quanto a viagens, praças ou clientes .

- Sistema de remuneração dos vendedores: quanto mais a renda do vendedor depender de um plano de incentivos, prêmios ou bônus, tanto mais a segmentação deverá ser orientada no sentido de oferecer oportunidades iguais aos vendedores. Se, ao contrário, a remuneração fôr fixa, a equiparação de oportunidades nas diversas zonas é menos importante.

- Vias de distribuição: a venda direta exige maior corpo de vendedores; por conseguinte, as zonas devem ser me- 
nores. Quando vários intermediários participam do processo de distribuição as zonas podem ser maiores.

- Propaganda e promoção: se, em conseqüência das campanhas promocionais da emprêsa, os fregueses se tiverem acostumado a encaminhar seus pedidos diretamente ao escritório central ou às filiais, o número de visitas dos vendedores poderá ser reduzido e as zonas poderão ser ampliadas.

- Concorrência: quão mais forte fôr a posição de concorrentes em determinadas áreas, tão menores deverão ser as zonas nessas áreas, salvo se a emprêsa optar pela alternativa de concentrar esforços em regióes onde os competidores sejam menos bem representados.

2. Levantamento de dados externos - $O$ segundo passo do plano de segmentação consiste no levantamento de dados sôbre a demanda e a estrutura dos mercados que possam ser utilizados na avaliação dos potenciais das diversas praças. Para a maioria das nossas emprêsas êsse é o calcanhar-de-aquiles da segmentação, seja por não confiarem nos dados estatísticos, seja por terem dificuldades em levantá-los. No entanto, a coleta de dados secundários de fontes oficiais ou semi-oficiais é compensatória sempre que haja uma ou várias das seguintes condições:

- quando o custo de distribuição representa parcela considerável do custo total;

- quando a emprêsa procura atingir ampla cobertura geográfica na distribuição de seus produtos;

- quando a concorrência é intensa;

- quando os dados podem ser utilizados para outros fins administrativos, tais como orçamentos, planejamentos de produção e de estoques, previsão de vendas e determinação de cotas;

- quando pode ser comprovado um elevado grau de correlação entre um ou vários dados secundários e a demanda dos produtos. 
O último dêsses aspectos merece ser destacado, pois, ao que parece, é muito restrito o número de emprêsas que está tirando proveito direto da possível correlação existente entre a procura de seus bens e o comportamento de um ou vários índices econômicos. Fatôres como depósitos bancários, registro de automóveis, grau de eletrificação e, em alguns casos, arrecadação de impostos e até mesmo a produção industrial prestam-se muito como variáveis independentes no cálculo da correlação entre vendas esperadas e o poder aquisitivo dos mercados.

O Instituto Pinheiros, por exemplo, fêz várias tentativas para equacionar seu potencial por meio de dados secundários, até descobrir uma fórmula simples que há vários anos vem sendo utilizada para medir potenciais regionais. Essa fórmula conjuga o número de farmácias com o número de médicos registrados nas cidades em que a emprêsa distribui seus produtos.

Além das fontes secundárias, a emprêsa pode, naturalmente, levantar seus próprios dados por meio da pesquisa mercadológica junto ao seu campo de ação. Por serem onerosas, nem tôdas as emprêsas têm condições para promover pesquisas com o fito exclusivo de orientar-se na segmentação. Não obstante, pesquisas são compensatórias numa ou mais das seguintes condições:

- quando o número potencial de fregueses é limitado (consumidores de bens industriais, por exemplo);

- quando a área geográfica a ser coberta é restrita (por exemplo, os bairros de uma cidade em que se distribuam bens de conveniência);

- os resultados da pesquisa são úteis para várias tomadas de decisões (por exemplo, grau de aceitação de um produto nôvo, teste de uma embalagem, medição da fôrça de concorrentes, contrôle de vendas etc.).

Nada impede, naturalmente, que uma emprêsa opere com dois ou até três tipos de dados para segmentar o seu mercado. Nesse caso os dados secundários ou primários devem constituir a base para avaliação, e as vendas passadas fa tôres de ajuste. 
3. Determinação dos índices regionais - A partir dos dados colhidos sôbre os potenciais, a emprêsa pode agrupar os mercados regionais em várias classes, seja em função do volume de vendas (em unidades ou cruzeiros) absorvível por mercado, seja à base de percentagens sôbre um total a ser estabelecido. Êsse total deve resultar da determinação dos potenciais.

Suponhamos, por exemplo, que uma emprêsa denominada ALFA S.A. tenha desenvolvido uma equação que the haja permitido estabelecer índices de potencial aplicáveis a todos os segmentos do mercado a ser coberto. A soma dos índices corresponde, digamos, a 53497 . Por conseguinte, o potencial de um mercado regional $X$, cujo índice acuse o coeficiente de 1432 , deve ser equivalente a 2,68\% do potencial total. Suponhamos, ainda, que o volume de produção a ser distribuído num período predeterminado (geralmente de um ano) seja de 1 milhão de unidades. Nesse caso o mercado $X$ deverá absorver 26768 unidades, isto é, $2,68 \%$ do total a ser produzido. Finalmente, suponhamos que a emprêsa tenha resolvido desdobrar seus mer cados regionais em 5 classes de acôrdo com os critérios indicados no Quadro 1.

Quadro 1: AlFA S. A. - Classiticação dos Mercados Regionais

\begin{tabular}{|c|c|c|c|c|c|c|}
\hline \multirow{2}{*}{ Classe } & \multicolumn{2}{|c|}{$\begin{array}{c}\text { CRITÉRIOS DE } \\
\text { CLASSIFICAÇÃo }(\%)\end{array}$} & \multicolumn{2}{|c|}{$\begin{array}{c}\text { VOLUME DE ABSORÇÃO } \\
\text { (UNIDADES) }\end{array}$} & \multicolumn{2}{|c|}{$\begin{array}{l}\text { COEFICIENTE DO } \\
\text { POTENCIAL }\end{array}$} \\
\hline & Minimo & Máximo & Mínimo & Máximo & Mínimo & Máximo \\
\hline A & 10,1 & - & 101.000 & - & 5.351 & - \\
\hline B & 5,1 & 10,0 & 51.000 & 100.000 & 2.671 & 5.350 \\
\hline $\mathrm{C}$ & 3,1 & 5,0 & 31.000 & 50.000 & 1.601 & 2.670 \\
\hline $\mathrm{D}$ & 1,1 & 3,0 & 11.000 & 30.000 & 551 & 1.600 \\
\hline $\mathbf{E}$ & 0,5 & 1,0 & 5.000 & 10.000 & 270 & 540 \\
\hline
\end{tabular}

O exemplo vem demonstrar que a avaliação dos potenciais não revela, necessàriamente, a capacidade máxima 
de um mercado regional para absorver determinado bem em unidades ou cruzeiros. O que ela determina é a capacidade de absorção relativa dêsses mercados em função de um total que denominamos coeficiente de potencial. No caso do exemplo acima, portanto, apenas podemos afirmar que o mercado $X$ pertence ao grupo $C$ e que nêle devemos vender cêrca de 26770 unidades do total a ser produzido, se quisermos distribuir nossos esforços de venda de maneira condizente com os potenciais regionais relativos à nossa capacidade de produção. Isso não impede que, na realidade, o mercado $X$ (como todos os outros) seja capaz de absorver volume maior do que 26770 unidades, ou até menor, caso ocorra uma recessão econômica ou se os concorrentes trabalharem de maneira mais eficiente do que nós.

\section{B) Decisões sôbre a Cobertura Geográfica}

Com a execução dos primeiros três passos serão alcançados dois dos objetivos fundamentais do modêlo proposto: a concatenação numérica dos dados regionais e o equacionamento dos potenciais relativos. Ao classificar os mercados em grupos (a exemplo dos dados do Quadro 1), a emprêsa pode obter uma visão de conjunto do mercado total e da concentração de poder aquisitivo das diversas áreas geográficas .

Todavia, na maioria das emprêsas, a segmentação não é nem deve ser feita exclusivamente em função dos potenciais regionais. Várias outras considerações entram em jôgo ao se determinarem as zonas definitivas. Essas considerações são de natureza essencialmente administrativa, como a determinação das diretrizes de segmentação, a seleção dos mercados a serem cobertos, a seleção dos centros regionais de operação e, finalmente, o equipamento dos. mercados em tôrno de seus centros.

4. Determinação das diretrizes de penetração regional - A maneira pela qual uma emprêsa deseja penetrar no mercado exerce influência decisiva no plano de segmentação geográfica. Em princípio, a penetração pode ser 
ou restritiva e intensa, ou seletiva e ampla. Assim, por exemplo, uma emprêsa poderá determinar que a forma mais desejável de penetração consiste em concentrar esforços mercadológicos na conquista dos mercados localizados nas imediações da fábrica, apesar de saber que certos mercados mais distantes lhe ofereçam potencial satisfatório ou até amplo. Em decorrência dessa decisão restritiva o processo de mercadização dos produtos sofrerá modificações: as vias serão, provàvelmente, mais curtas; o número de vendedores próprios terá de ser maior; a seleção dos fregueses far-se-á por critérios menos rígidos; e a promoção será mais concentrada do que no caso de uma penetração menos intensa e geogràficamente mais ampla .

A política de penetração nos mercados dependerá de uma série de considerações de ordem estratégica, como planos de expansão, aproveitamento de recursos disponíveis ou o desejo de evitar que concorrentes atinjam posição favorável em determinadas regiões.

Independentemente dessas considerações, convém que a emprêsa estabeleça uma diretriz quanto à relação entre as despesas diretas com vendas e o volume esperado de vendas. Podemos, por exemplo, imaginar que uma emprêsa tenha estabelecido uma taxa máxima de $20 \%$ para a cobertura das despesas com vendedores mais o custo de transporte das mercadorias. Imaginemos, no caso, que determinada praça deva absorver $\mathrm{Cr} \$ 1$ milhão durante um período futuro. Se as despesas diretas de venda necessárias para atingir êsse volume excederem Cr $\$ 200 \mathrm{mil}$, a praça deverá ser abandonada ou coberta por outros meios, talvez por atacadistas .

É evidente que a formulação de diretrizes dessa natureza não só contribui para a racionalização do processo de vendas, como facilita a tarefa de segmentação.

5. Seleção dos mercados e determinação das "metas de penetração regional" - Além dos potenciais, a emprêsa pode-se basear em vários outros critérios ao selecionar os mercados em que pretenda operar. Em parte, a escolha dêsses critérios dependerá de condições internas, como dos 
objetivos e dos sistemas de distribuição em vigor, ou da disponibilidade de recursos humanos, técnicos e financeiros. Todavia, três costumam ser os fatôres que merecem especial cuidado na seleção dos mercados regionais brasileiros: a facilidade de acesso aos mercados, o número dos clientes e a capacidade financeira dêstes .

Assim, por exemplo, a emprêsa ALFA S.A. poderá determinar que: $10^{\circ}$ ) só deverão ser cobertos pela organização os mercados do grupo $E$ que se situem próximos a uma praça pertencente a um dos grupos $A, B$ ou $C ; 2 .^{\circ}$ ) as praças do grupo $E$ ou $D$ só deverão ser incluídas na segmentação se os custos diretos de locomoção do corpo de vendedores e do transporte de bens não excederem $10 \%$ do custo total de distribuição.

Ademais, o número e o poder financeiro dos clientes podem exercer ponderável influência na segmentação. É natural que uma emprêsa, ao escolher entre duas praças de igual potencial e igual facilidade de acesso, deve dar preferência àquela que congregue maior número de clientes financeiramente poderosos, sobretudo se pontuais na liquidação de suas obrigações creditícias .

Uma vez que a emprêsa tenha procedido à seleção dos mercados, cabe-lhe determinar o que denominamos "metas de penetração regional”.

As metas de penetração regional resultam da combinação dos fatôres que determinam o volume de vendas a ser realizado em uma praça durante um período prefixado. Dentre êsses fatôres podemos mencionar, além do potencial: o número de clientes, o seu poder aquisitivo, a encomenda média por visita realizada, o número de visitas necessárias para a realização de determinado volume, e quaisquer outros aspectos que facilitem a quantificação das vendas previstas para cada cliente em potencial.

O exemplo que adiante vamos analisar demonstra como as metas regionais podem ser utilizadas na prática administrativa. Aqui desejamos focalizar apenas alguns aspectos genéricos sôbre a determinação das metas e suas vantagens administrativas, quais sejam: 
- Geralmente a meta não coincide com o potencial da região en virtude dos reajustes decorrentes da adaptação das fôrças internas (por exemplo, número de vendedores) às fôrças externas (por exemplo, número e localização dos clientes ).

- As vendas realizadas aos clientes durante um período passado são, por vêzes, bastante úteis para o trabalho de ajuste, se bem que não devam ser aplicadas diretamente, por refletirem as eventuais deficiências do sistema de distribuição em vigor. Um confronto entre o potencial e as vendas passadas costuma ser o meio mais eficiente para determinação das metas .

- O levantamento das metas é trabalhoso, mas compensatório quando posteriormente utilizado na racionalização do sistema de distribuição para, por exemplo, classificar e selecionar clientela, determinar cotas de vendas, vincular cotas de propaganda a determinadas praças ou avaliar o esfôrço de vendas em geral.

6. Seleção dos centros operacionais - Algumas emprêsas conseguem controlar seu mercado, eficientemente, a partir de um único centro de operação: o escritório central ou a fábrica. Para elas a sexta fase de segmentação pode ser eliminada. Muitas outras emprêsas, contudo, só pcidem tornar-se eficientes na distribuição quando instalam centros intermediários de operação e contrôle, por meio de filiais, agências ou depósitos. A determinação das metas constitui a principal base para a seleção dêsses centros operacionais (ou "peões" como alguns administradores os chamam).

O centro é um local que se destaca econômicamente em l:ma região, em virtude do elevado grau de urbanização e do estado mais avançado das suas atividades produtivas e comerciais, o que o predestina a ser selecionado como ponto de contrôle do processo distributivo de uma região. Geralmente, a região subordinada a um centro é denominada território e é subdividida em zonas de venda.

Há casos em que a escolha dos centros é fácil. A maioria das nossas capitais estaduais prestam-se particularmente 
bem como centros de irraldiação dos mercados regionais, o que explica o grande número de filiais, armazéns, depósitos de representantes e atacadistas estabelecidos em cidades como Belo Horizonte, Salvador ou Pôrto Alegre. Em outros casos a seleção é difícil. Por exemplo, para a emprêsa que necessite de apenas um centro no Nordeste não será fácil a escolha entre cidades como Fortaleza, São Luiz ou Natal.

Dentre os múltiplos critérios de seleção dos centros destacamos os seguintes:

- proximidade de localização de mercados regionais de potencial suficientemente elevado;

- vias de acesso, custo de locomoção de vendedores (ou representantes ) e custo de transporte dos produtos;

- grau de penetração desejado pela emprêsa em face das diretrizes de segmentação, escolha das vias, disponibilidades financeiras, concorrência e outros fatôres internos e externos que só parcialmente dependam dos potenciais regionais;

- conveniências de ordem pessoal dos inspetores de venda ou dos próprios vendedores, tais como o tipo de condução a ser utilizado ou as relações com os clientes.

7. Agrupamento dos mercados regionais - Na prática as fases 6 e 7 do plano de segmentação costumam ser conduzidas simultâneamente, pois a escolha dos centros depende, em parte, do agrupamento dos mercados regionais, ou seja, da sua vinculação a um ou a outro centro.

Ao agrupar os mercados, a emprêsa deve ter em mente os custos de distribuição, que, dentre outros fatôres, decorrem da distância a ser vencida pelos vendedores e pelas próprias mercadorias. Por vêzes, um mercado de potencial satisfatório deve ser abandonado por fôrça dos elevados custos decorrentes da distância que o separa do centro. Em outros casos o próprio centro pode ser deslocado para assegurar melhor distribuição dos potenciais regionais.

A técnica de agrupamento dos mercados varia conforme a natureza do produto e o sistema de distribuição. E claro 
que as zonas de venda e, por conseguinte, os próprios territórios podem abranger regióes mais amplas quando a emprêsa opera com atacadistas em lugar de vendedores próprios, quando o número de visitas não é freqüente ou quando as vias de acesso são particularmente boas .

Embora o agrupamento não exija conhecimento ou preparo técnico especiais - pois, em última análise, depende do senso comum - essa fase final da segmentação é, por vêzes, bastante trabalhosa e seu resultado de importância decisiva para o sucesso do plano de segmentação, uma vez que dêle dependem numerosos fatôres que determinarão a futura eficiência da segmentação, tais como os caminhos a serem percorridos, o tempo a ser gasto por visita ou o número de clientes que possam ser visitados por período.

O exemplo que segue demonstrará mais claramente como a função do agrupamento pode ser exercida a partir de um objetivo que vise ao melhor aproveitamento dos recursos à disposição de uma emprêsa .

\section{UM EXEMPLO DE SEGMENTAÇÃO}

Imaginemos uma emprêsa produtora de bens de conveniência (alimentos, cigarros, produtos farmacêuticos, pequenos aparelhos eletrodomésticos) que distribua seus produtos em âmbito nacional quase exclusivamente por uma equipe de vendedores próprios, supervisionada por inspetores que operem em seus respectivos centros de contrôle. Denominaremos a emprêsa de INDÚSTRIA XY.

O problema básico pode ser assim formulado: segmentar os mercados regionais em zonas de venda para atingir o máximo aproveitamento de seu corpo de vendedores e uma cobertura de mercado condizente com o potencial disponível. No caso devemos partir das seguintes premissas de distribuição, derivadas de experiências observadas:

- os varejistas devem ser visitados, de preferência, uma vez por semana ou, no mínimo, uma vez por mês quando os custos de venda não comportem visitas mais freqüentes; 
- a cada vendedor devem ser dadas oportunidades mais ou menos iguais de realizar vendas;

- cada zona deve corresponder à capacidade de venda de um vendedor, levando-se em conta o potencial e os obstáculos relativos de acesso aos varejistas;

- cada zona deve ser atribuída a um só vendedor.

Além dessas premissas, uma análise das vendas do passado revelou que:

- cada vendedor podia realizar, em média, 10 visitas diárias, ou 50 visitas semanais, ou 200 visitais mensais, desde que a distância entre os pontos de venda fôssem relativamente pequenas, como nas cidades de maior concentração de estabelecimentos varejistas;

- a encomenda média por visita variava de modo mais ou menos proporcional ao potencial total da cidade em que se localizassem os varejistas; nas cidades menores, porém, aumentava de conformidade com o aumento do intervalo entre as visitas.

Partindo dessas observações, a emprêsa classificou os mercados em cinco grupos com as seguintes caraterísticas:

$\begin{array}{ccc}\text { Classe } & N .^{\circ} \text { de Varejistas } & N .^{\circ} \text { de Visitas } \\ \text { A } & \text { acima de } 100 & 1 \text { por semana } \\ \text { B } & 51-100 & 1 \text { por semana } \\ \text { C } & 31-50 & 1 \text { cada } 15 \text { dias } \\ \text { D } & 15-30 & 1 \text { cada } 15 \text { dias } \\ \text { E } & \text { abaixo de } 15 & 1 \text { por mês }\end{array}$

Além dêsses cinco grupos, havia a classe $F$, que incorporava as praças onde a emprêsa não mantinha vendedores próprios por julgar o volume de vendas excessivamente baixo em função das despesas de distribuição. Nessas praças os produtos eram distribuídos por atacadistas.

Nas cidades pertencentes aos grupos $A$ e $B$ mesmo os pequenos varejistas - que encomendavam volumes médios relativamente baixos por visita - eram visitados uma vez 
por semana, porque o custo adicional dessas visitas era diminuto por causa da grande concentração dos clientes e pela conveniência de uma promoção e de um contrôle mais freqüentes. Pela mesma razão todos os clientes das cidades dos grupos $C$ e $D$ eram visitados de 15 em 15 dias. Verifica-se, em resumo, que uma zona de venda equivale a um potencial de 200 visitas mensais nas cidades que comportam a manutenção de pelo menos um vendedor, e que as diversas zonas deviam ter potenciais aproximadamente iguais. Nas zonas que abrangessem duas ou mais cidades de potencial inferior a 200 visitas o número destas teria de ser diminuído em função do tempo necessário para as viagens entre as cidades onde os vendedores estivessem domiciliados (chamadas "cidades-bases") e as. cidades pertencentes a suas zonas.

QuAdro 2: Ficha de Metas de Penetração

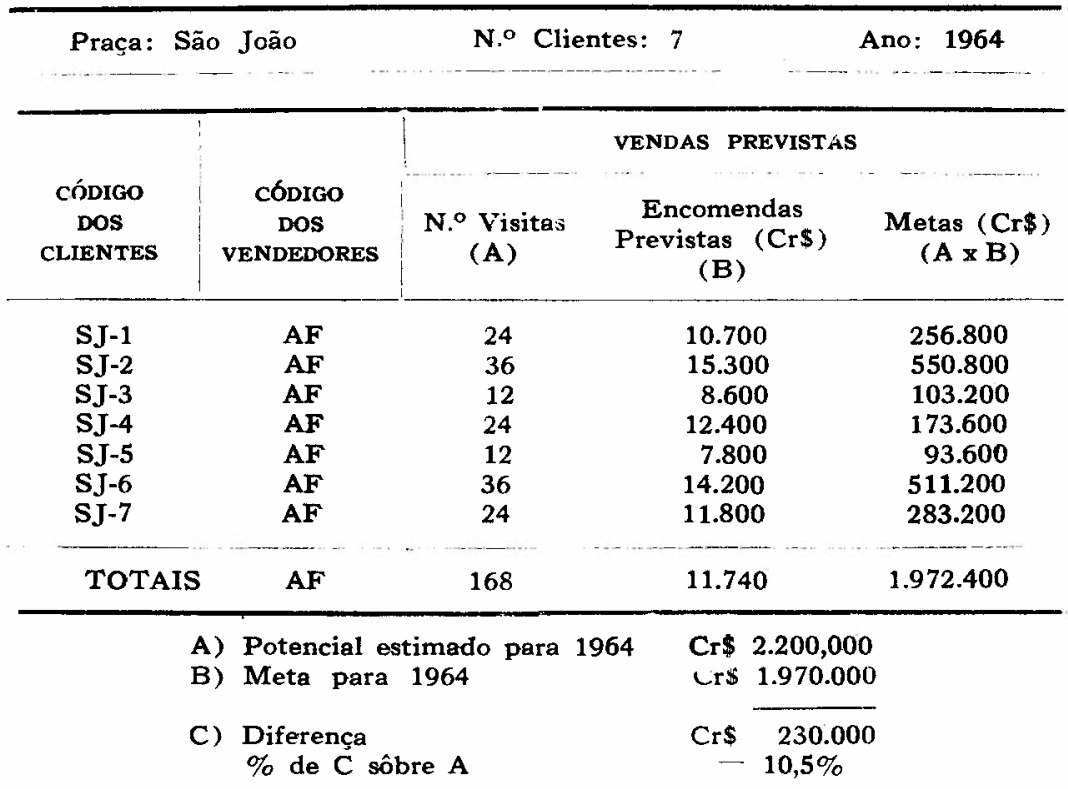

A partir dêsses dados a INDÚSTRIA XY prosseguiu da seguinte maneira para segmentar o seu mercado, sob o princípio da distribuição mais eficiente de seu corpo de vendedores em função dos potenciais disponíveis: 
1. Para tôdas as cidades a serem cobertas pela segmentação foram preparadas "fichas de metas de penetração" de acôrdo com o modêlo apresentado no Quadro 2 .

2. Com base nessas fichas as cidades foram classificadas de acôrdo com as caraterísticas acima descritas.

3. Um mapa do Brasil, demarcatório das vias de transporte, foi utilizado para identificar as cidades dos cinco grupos ( $A$ a $E$ ) por meio de alfinêtes coloridos.

4. Os centros de operação foram escolhidos segundo três critérios: potencial, grau de urbanização e ligações com cidades circunvizinhas .

5. Um agrupamento preliminar foi feito exclusivamente à base das indicações pelo mapa .

6. Uma avaliação mais minuciosa de cada território foi feita em função do número de visitas a serem realizadas em cada cidade e das vias de acesso entre o centro e as cidades secundárias. Em conseqüência dessa avaliação as estruturas de alguns territórios foram alteradas.

7. Cada território foi segmentado em função das visitas médias mensais a serem realizadas em cada cidade.

8. Adaptações finais dos territórios e das suas respectivas subdivisões em zonas de venda foram feitas para assegurar melhor aproveitamento dos vendedores e para levar em conta algumas condições internas (como relações entre vendedor e cliente) e externas (como posição de concorrentes) da emprêsa.

Para melhor ilustrar os últimos passos do esquema acima resumido descrevemos os procedimentos de segmentação de uma das regiões, denominada Território III .

A Figura 2 mostra o Território III composto de 20 cidades. A Cidade 1 foi escolhida por centro; uma rodovia pavimentada liga as Cidades 1 e 2 . Um estrada de ferro, além de uma estrada não pavimentada, atravessa as $\mathrm{Ci}$ dades 1 e 3; as outras 17 cidades são ligadas ou a uma das três cidades principais, ou entre si, por estradas de rodagem geralmente não pavimentadas. 


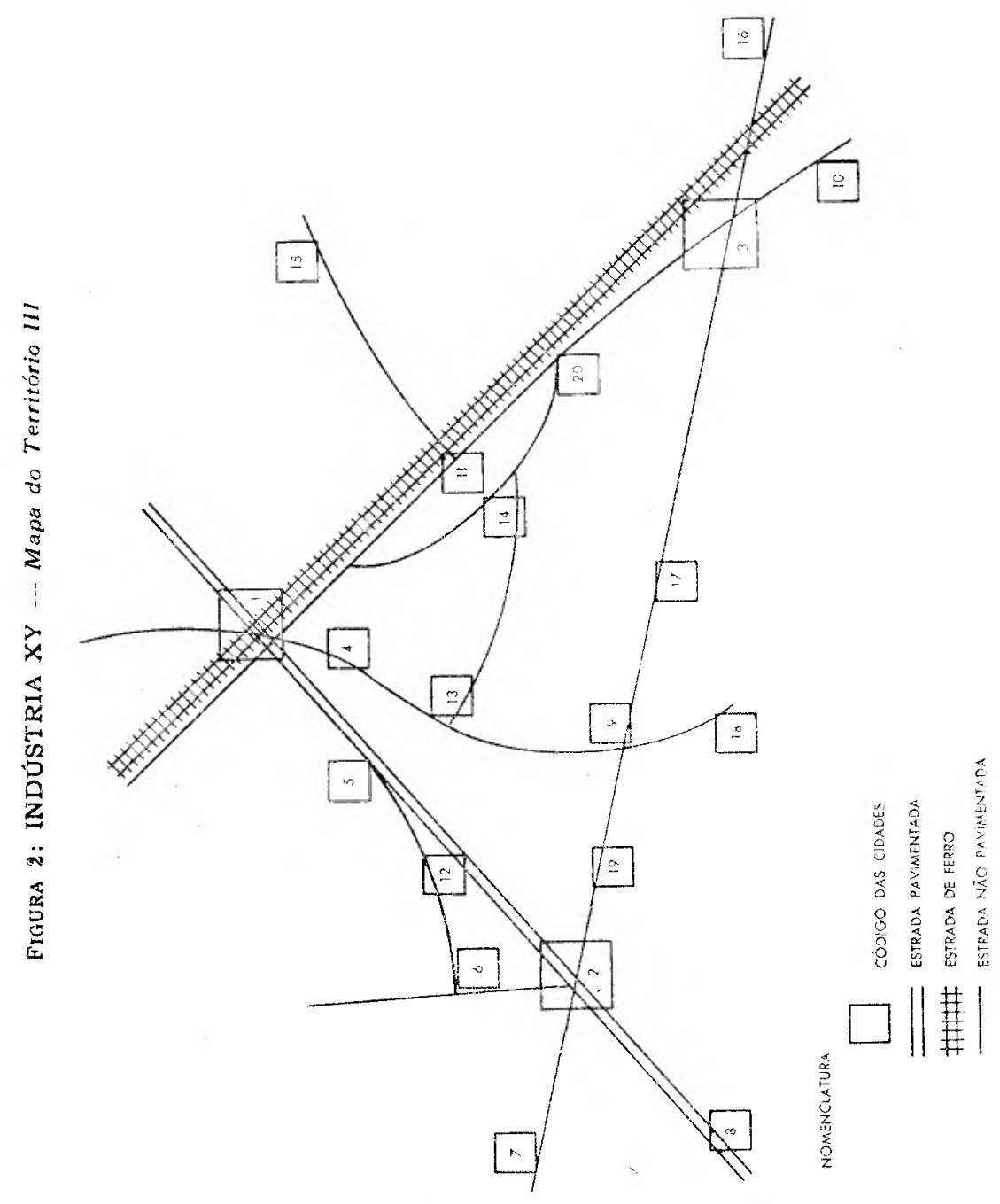




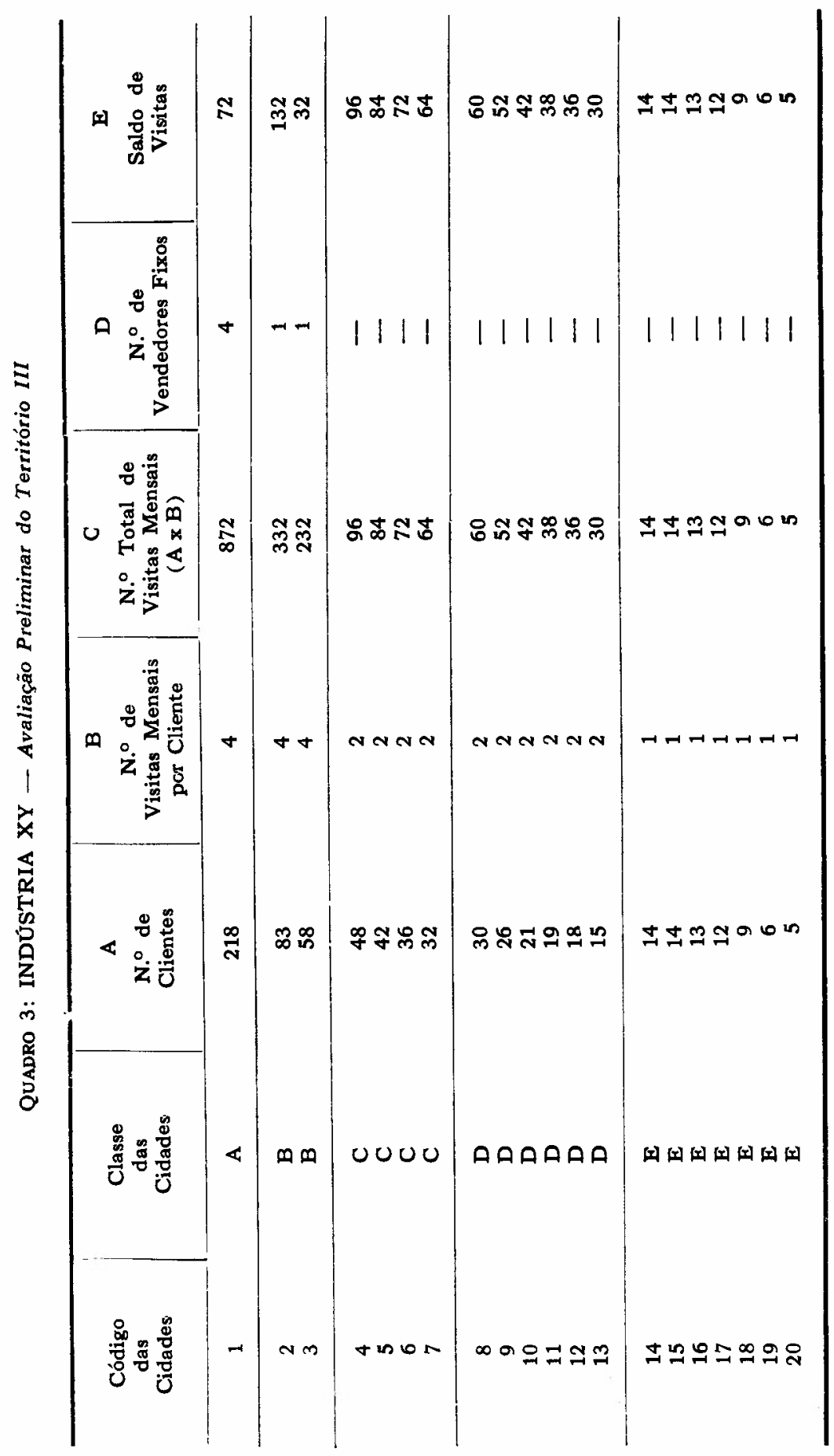




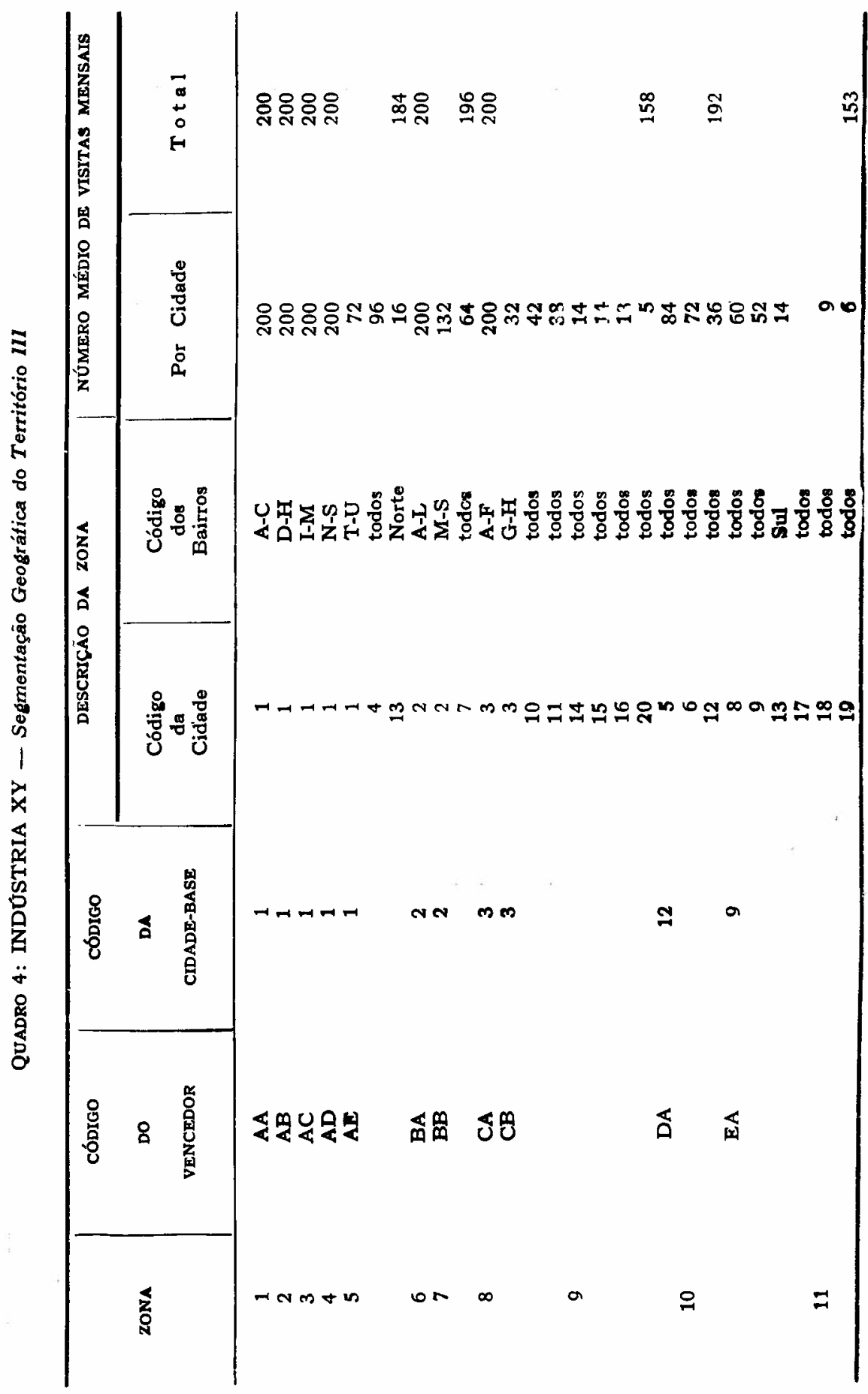


A tarefa que se apresentava ao analista consistia em segmentar o mercado de tal forma que a emprêsa pudesse tirar o máximo proveito dos potenciais regionais com custos mínimos de distribuição.

O próprio mapa sugere alguns agrupamentos aparentemente ideais. Assim, por exemplo, as Cidades 4 e 5 deveriam ser subordinadas à Cidade 1 , e as Cidades 7,8 e 19 à Cidade 2. Menos aparentes eram os agrupamentos das Cidades 9, 12, 14 e 15. Além disso, a proximidade de uma cidade menor a uma cidade maior não deveria ser o único critério de agrupamento, pois em alguns casos era possível que isso forçasse a emprêsa a contratar vendedores que só parcialmente seriam aproveitados.

Além da distância entre as cidades, outro critério de agrupamento teria de ser o melhor aproveitamento do corpo de vendas. A base de avaliação dêsse segundo critério era o número médio mensal de visitas a serem realizadas na cidade-base (200) ou nas cidades secundárias (200 menos um fator que levava em conta a distância entre a cidade-base e a cidade secundária) .

Estabelecidos os critérios, foi preparada uma relação das vinte cidades do território (vide Quadro 3), que revelou quantas visitas deviam ser realizadas em cada cidade. $O$ centro necessitava de, pelo menos, quatro vendedores ( $872: 200=4+$ um saldo de 72 visitas mensais), e as Cidades 2 e 3 precisavam, cada uma, de — no mínimo - um vendedor.

Em etapa final a região foi dividida em onze zonas de vendas determinadas em função do número médio de visitas e das necessidades de viagem entre as cidades de menor potencial. O resultado dessa segmentação foi transcrito no Quadro 4, cuja análise revela os seguintes aspectos:

- o zoneamento das três maiores cidades (1, 2 e 3 ) obedece a uma divisão por bairros;

- a Cidade 5, apesar de sua localização próxima ao centro (Cidade 1), foi incorporada à zona do vendedor DA, sob cujo contrôle ficaram as Cidades 5,6 e 12 por serem 
próximas e por comporem um mercado de potencial adequado (192 visitas mensais) para um vendedor;

- a Cidade 13, embora pequena, foi dividida em duas partes para evitar a sobrecarga do vendedor AE (que ficou apenas com a região norte da cidade) e oferecer me1hor oportunidade ao vendedor EA (a quem se atribuiu a região sul) .

Verifica-se, em resumo, que a INDÚSTRIA XY conseguiu segmentar o Território III de maneira bastante racional, dividindo-a em onze zonas com raios de ação bem limitados e de tamanhos quase iguais. Os vendedores (CB e EA, por exemplo) obrigados a servir um mercado mais disperso e cujo número de visitas tinha de ser inferior à média, contavam, na realidade, com potencial maior do que o indicado pelo número de visitas, pois suas zonas incluíam cidades visitadas apenas uma ou duas vêzes por mês e onide as encomendas médias por visita tendiam a ser maiores. Onde isso não ocorresse o sistema de determinação de cotas procurou compensar a falta de potencial por uma cota de vendas mínima mais baixa, combinada com uma comissão progressiva que lhes oferecesse a possibilidade de alcançar remuneração igual ou até superior à dos vendedores localizados nas cidades maiores .

\section{ALGUMAS EXPERIENCIAS EM SEGMENTAÇÃO}

Com o intuito de colhêr material para a elaboração de uma pesquisa ${ }^{1}$ recorremos recentemente a várias emprêsas nacionais que gentilmente nos ofereceram, entre outros dados, informações sôbre a técnica e a problemática da divisão do seu mercado em regiões, territórios ou zonas de venda. Dentre essas emprêsas selecionamos sete organizações que operam com linhas de produtos diferentes e

1) A pesquisa em questão está sendo conduzida pelo Prof. Dole A. ANderson e pelo autor, sob os auspícios da Fundação de Amparo à Pesquisa do Estado de São Paulo. A partir de dados secundários referentes aos principais municípios da Nação e de dad'os colhidos junto a um grupo selecionado de emprêsas, o projeto visa a desenvolver u'a metodologia capaz de determinar potenciais de mercado no Brasil. 


\begin{tabular}{|c|c|c|c|c|c|c|c|}
\hline 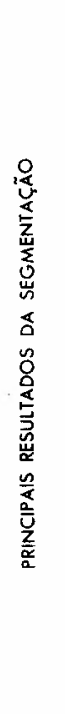 & 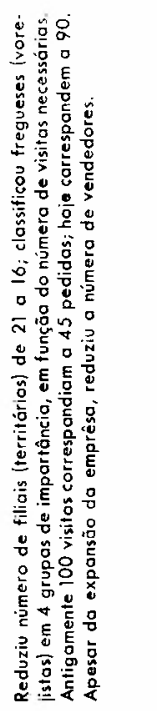 & 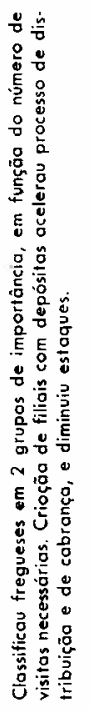 & 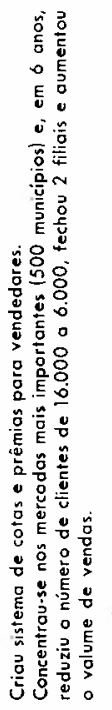 & 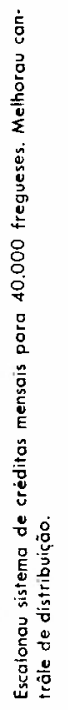 & 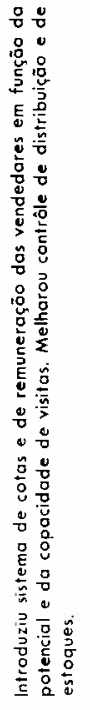 & 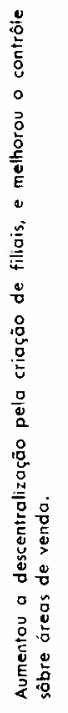 & 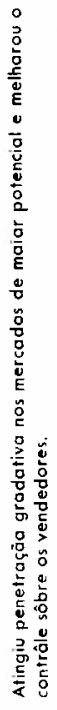 \\
\hline 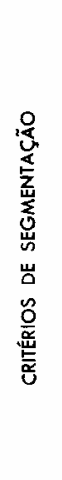 & 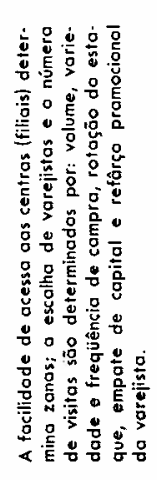 & 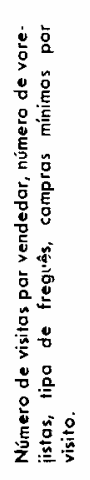 & 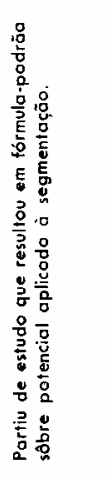 & 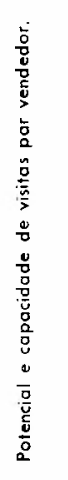 & 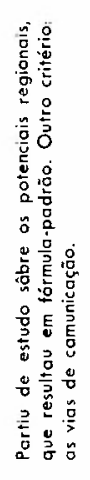 & 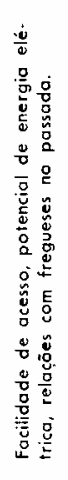 & 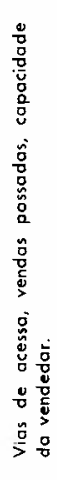 \\
\hline 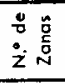 & $\stackrel{\circ}{ }$ & $\stackrel{ }{=}$ & & $\stackrel{\circ}{\underline{I}}$ & 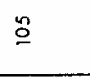 & $\tilde{\infty}$ & $a$ \\
\hline 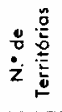 & $\simeq$ & $=$ & $\stackrel{\circ}{ }$ & $a$ & $\underline{\sigma}$ & $\infty$ & $\simeq$ \\
\hline $\begin{array}{l}\frac{a}{0} \\
\frac{0}{3} \\
\frac{0}{2} \\
\frac{2}{2}\end{array}$ & 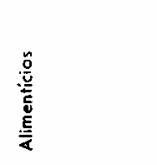 & 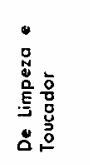 & 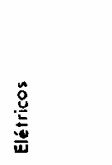 & 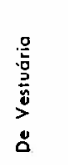 & 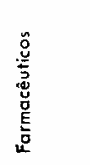 & 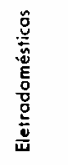 & 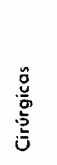 \\
\hline 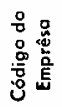 & $\ll$ & $\infty$ & $u$ & 0 & $\omega$ & $\mu$ & 0 \\
\hline
\end{tabular}


cujo sistema de segmentação geográfica nos pareceu particularmente bem elaborado e útil como ponto de partida na composição do modêlo.

O Quadro 5 oferece-nos um resumo dos principais aspectos da segmentação dessas sete emprêsas que têm as seguintes carateristicas comuns: tôdas podem ser consideradas "grandes" e distribuem, em âmbito nacional, duas ou mais linhas de bens de consumo, utilizando-se quase exclusivamente da via fábrica-filiais regionais-revendedores-consumidores finais. Três delas distribuem uma parcela de seus produtos por meio de atacadistas ou agentes.

Das informações particularizadas do Quadro 5 podemos tirar as seguintes observações de natureza genérica:

- Os territórios (ou regiões) são caraterizados pela existência de uma filial e, geralmente, de um depósito ou armazém, donde são distribuídos os produtos destinados às zonas pertencentes ao território.

- Não só os tamanhos, das zonas, mas também a distribuição territorial varia consideràvelmente de emprêsa para emprêsa, dependendo dos objetivos de cobertura de mercado, tipos de produto, critérios de avaliação do potencial, localização e dispersão das praças, facilidade de acesso aos mercados centrais e outros fatôres.

- $\quad$ fato de a maioria das sete emprêsas aqui consideradas terem um número semelhante de territórios e de zones não é, naturalmente, representativo para a emprêsa bramileira, nem deve ser considerado como "ideal". Êsse fato pode ser atribuído às semelhanças mercadológicas das sete companhias .

- O tamanho das zonas é determinado por alguns critérios bastante semelhantes entre as emprêsas, entre os quais destacamos: número e tipos de fregueses, sua capacidade de compra (geralmente avaliada pelas encomendas médias do passado), facilidade de comunicação entre as zonas e a filial e, sobretudo, capacidade dos vendedores para efetuar visitas, pois na maioria dos casos atribui-se uma zona a um só vendedor. 
- O número médio de zonas por território gira em tôrno de 10 a 12 , o que parece indicar que essa proporção oferece as melhores condições de contrôle para o gerente de filial.

- Várias das emprêsas operam com inspetores (ou monitores de venda, sendo que no caso da EMPRÊSA A um inspetor supervisiona 5 vendedores. Nessa emprêsa o tempo médio por visita é de 20 minutos.

- Tôdas as emprêsas se beneficiaram, direta ou indiretamente, com a segmentação geográfica (vide a última coluna do Quadro 5), se bem que em graus diferentes. A racionalização do sistema de distribuição e a consequiente diminuição do custo de venda por visita realizada é o principal resultado do sistema.

Devemos, também, mencionar que a maioria das emprêsas levou vários anos para chegar ao estado de segmentação em vigor. Ademais, não considera êsse estado integralmente satisfatório ou definitivo. A segmentação geográfica é, sem dúvida, um instrumento que pode e deve ser contìnuamente aperfeiçoado em função de novos dados secundários publicados sôbre o potencial dos mercados regionais, da interpretação dos resultados à previsão de vendas, da determinação de cotas, e das alterações de ordem interna (por exemplo, lançamento de novos produtos) e externa (construção de estradas ou mudança no poder aquisitivo) que afetem a estrutura mercadológica e a demanda regional.

\section{CONCLUSŌES}

Ao concluir êste trabalho desejamos focalizar um princípio da segmentação geográfica que parece ter poucos adeptos no Brasil. Afirma êsse princípio que o zoneamento de vendas é compensatório mesmo para as emprêsas que costumam "vender tudo" (ou seja, que operam em mercado vendedor), isto porque a segmentação pode exercer profunda influência sôbre a lucratividade da emprêsa, qualquer que seja o mercado em que ela opere. Sua finali- 
dade não consiste apenas no aproveitamento adequado dos potenciais regionais que se oferecem a uma emprêsa e aos seus concorrentes: consiste, também, na racionalização da política mercadológica, no escalonamento dos créditos e cobranças e no conrôle do processo mercadológico em geral. Em conjunto, êsses fatôres são decisivos para a redução dos custos de distribuição, o que, por sua vez, é uma das condições básicas para que o País possa entrar, nos próximos decênios, numa nova fase de evolução econômica, para a qual desde já precisamos começar a nos preparar: a da produção e mercadização em larga escala. 